\title{
PROCESSO DE PAZ NA COLÔMBIA: UMA ANÁLISE À LUZ DO DIREITO INTERNACIONAL HUMANITÁRIO
}

\section{PEACE PROCESS IN COLOMBIA: AN ANALYSIS IN THE LIGHT OF THE INTERNATIONAL HUMANITARIAN LAW}

\author{
Ana Carolina Ribas \\ Universidade Federal do Paraná - UFPR (Curitiba, PR, Brasil) \\ Ana Paula Luciani de Carvalho \\ Universidade Federal do Paraná - UFPR (Curitiba, PR, Brasil) \\ Larissa Ramina \\ Universidade Federal do Paraná - UFPR (Curitiba, PR, Brasil)
}

Recebimento: 22 fev. 2017

Aceitação: 17 maio 2017

\begin{abstract}
Como citar este artigo / How to cite this article (informe a data atual de acesso / inform the current date of access):
RIBAS, Ana Carolina; CARVALHO, Ana Paula Luciani de; RAMINA, Larissa. Processo de paz na Colômbia: uma análise à luz do Direito Internacional Humanitário. Revista da Faculdade de Direito UFPR, Curitiba, PR, Brasil, v. 62, n. 1, jan./abr. 2017, p. 273 - 298. ISSN 2236-7284. Disponível em: <http://revistas.ufpr.br/direito/article/view/50863>. Acesso em: 30 abr. 2017. DOI: http://dx.doi.org/10.5380/rfdufpr.v62i1.50863.
\end{abstract}

\section{RESUMO}

O presente artigo tem como objetivo a análise do processo de paz na Colômbia sob a luz do Direito Internacional Humanitário e dos principais documentos internacionais sobre a matéria. A partir da retomada dos antecedentes históricos da formação dos grupos armados, com destaque para as FARC, das negociações intentadas desde a década de 80 e do plebiscito realizado ao final de 2016, busca-se estruturar as bases do conflito, a fim de que seja possível sua classificação para o estabelecimento do regime jurídico aplicável. Tal perspectiva é embasada pelas disposições das Convenções de Genebra de 1949 e dos Protocolos Adicionais I e II, de 1977, que discorrem acerca das características e critérios para tipificação dos conflitos armados. Nesse contexto, mostra-se essencial a análise da atuação da Cruz Vermelha na Colômbia, tendo em vista seu papel de organização humanitária cujo mote é a proteção e assistência às vítimas de guerra e de outras situações de violência. Por fim, à luz do papel desempenhado pelo Comitê Internacional da Cruz Vermelha, serão trazidos alguns argumentos sobre os limites e possibilidades para efetivação dos termos firmados no acordo de paz.

\section{PALAVRAS-CHAVE}

Colômbia. Conflito armado. Processo de paz. Direito Internacional Humanitário.

\begin{abstract}
This article intends to analyze the peace process in Colombia in the light of the International Humanitarian Law and the main international documents on the subject. From the historical antecedents of the formation of the armed groups, especially the FARC, the negotiations launched since the 1980s and the plebiscite held at the end of 2016, its aim is to structure the foundations of the conflict in order to enable the establishment of the applicable legal regime. This perspective is
\end{abstract}


based on the provisions of the Geneva Conventions of 1949 and the Additional Protocols I and II of 1977, which discuss the characteristics and criteria for typifying armed conflicts. In this context, it is essential to analyze the function of the Red Cross in Colombia in view of its role as a humanitarian organization whose motto is the protection and assistance to victims of war and other situations of violence. Finally, in the light of the role played by the International Committee of the Red Cross, some arguments will be brought about the limits and possibilities for effective implementation of the terms of the peace agreement.

\section{KEYWORDS}

Colombia. Armed conflict. Peace process. International Humanitarian Law.

\section{INTRODUÇÃO}

Iniciado a partir de embates políticos entre grupos conservadores e liberais, o conflito desenvolvido na Colômbia tem seus primeiros sinais ainda no século passado. Desde sua origem voltada a questões político-sociais, evoluiu logo nos anos de 1960 para o armamento de grupos guerrilheiros e paramilitares, tornando-se o conflito armado que vigora há mais tempo na América Latina e um dos mais antigos do mundo (BBC, 2016a). À medida que foi se intensificando, adquiriu tamanha dimensão crônica que, ao desvirtuar alguns de seus escopos e diversificar suas formas de atuação, combate e financiamento, acabou por gerar consequências imensuráveis, vitimando a população de um país inteiro. Dentre os grupos guerrilheiros, ganhou destaque a atuação das Forças Armadas Revolucionárias da Colômbia (FARC), grupo que alcançou proporção suficiente para ser caracterizado como um movimento de libertação nacional (BORGES, 2006, p. 63).

Foi diante desse contexto que se desenvolveram as negociações entre o governo colombiano e as FARC, visando à promoção do cessar-fogo definitivo e de uma paz estável e duradoura (ECHANDÍA, 1999, p. 99-149). Depois de algumas tentativas, acertos e desacertos entre os principais atores do conflito, finalmente, em 2016, urgiu o acordo de paz entre a Colômbia e as FARC. Submetido à votação popular, que analisaria os termos desse acordo, tal não foi referendado (BBC, 2016b), tornando a situação ainda mais complexa e incerta (RML/EPD [tam], 2016).

Diante dessa conjuntura, especula-se que os motivos pelos quais a população colombiana deixou de aceitar os termos postos para o acordo estariam relacionados principalmente à incerteza da realização da justiça em relação às violações perpetradas durante o período. A compreensão de que o acordo de paz não é uma finalidade em si, mas, antes, um meio se iniciar um novo (e longo) caminho em direção à reestruturação social do Estado colombiano, é fulcral.

Ante essa realidade, o presente artigo busca, em um primeiro momento, a compreensão do desenrolar histórico das FARC na Colômbia. Para tanto, vale-se de uma breve análise do contexto 
que deu azo à sua formação para, em seguida, especular todas as fases da relação entre os governos colombianos e as FARC, culminando na assinatura do acordo de paz em 2016.

Na segunda parte do trabalho, integrando o estudo contextual à realidade jurídica, discorrese sobre o regime jurídico aplicável no caso do conflito armado colombiano. Nesse ponto são feitas, primeiramente, algumas considerações acerca das aproximações e divergências entre o Direito Internacional Humanitário (DIH) e o Direito Internacional dos Direitos Humanos (DIDH), buscandose compreender de que maneira interagem no contexto do conflito armado em questão (SWINARSKI, 1990). Em seguida, passam a ser analisados de maneira pormenorizada alguns pontos conceituais do conflito armado, sob as insígnias do DIH.

Com o aparato contextual e teórico desenvolvido no estudo, serão especulados os limites e possibilidades do acordo de paz recém-assinado. Isso porque, principalmente diante dos argumentos menos otimistas em relação ao acordo de paz, é preciso vê-lo antes como ponto de partida, e não ponto de chegada. É a partir dele que o povo colombiano voltaria a ter "uma oportunidade para construir uma sociedade que, após cinco décadas de guerra, possa voltar a conviver. Mas é também um caminho que se constrói com múltiplos significados” (COMITÊ INTERNACIONAL DA CRUZ VERMELHA, 2015).

Por fim, volta-se a atenção para a atuação do Comitê Internacional da Cruz Vermelha, uma vez que é ele o responsável pela promoção e aplicação do DIH (FERNANDES, 2006). Discorre-se ainda sobre a perspectiva a ser adotada nesse novo momento do processo de paz, a fim de que seja traçado o caminho para um desfecho satisfatório do conflito.

\section{CONFLITO ARMADO NA COLÔMBIA: ORIGENS E DESENVOLVIMENTO HISTÓRICO}

A compreensão do processo de paz na Colômbia, que envolve a negociação entre o seu governo e as FARC, não pode se dar de maneira apartada do contexto no qual esta foi organizada, bem como de seus princípios e valores constitutivos. O surgimento e evolução das FARC estão claramente marcados pelos intensos conflitos sociais colombianos (MARTON, 2016; NOGUERA, 2003, p. 2-4), sendo que a carência de investimentos sociais marca a gênese das questões que fundamentam a atuação e o fortalecimento dos grupos guerrilheiros (AMIN, 2004, p. 97). Convém mencionar, porém, que esse contexto não se restringe apenas às questões internas do Estado colombiano, incluindo também a conjuntura internacional e regional da segunda metade do século XX. 
Para Stephen Ferry, é curioso observar que a origem do conflito envolvendo as FARC se destaca por não ter raízes étnicas ou religiosas (FERRY, 2012). De acordo com Álvaro Villarraga, do Centro Nacional de Memória Histórica, três elementos são essenciais para a compreensão do conflito: a tendência do uso da violência no poder e na política, a não resolução sobre a questão da propriedade da terra no campo e a ausência de garantias para a pluralidade e exercício da política (COSOY, 2016).

Desde o início do século passado, a história colombiana foi marcada pelo enfrentamento entre liberalismo e conservadorismo. Em meados do século XX, tal embate passou a ser fortemente marcado pela violência, caracterizando, entre 1948 e 1950, o período que ficou conhecido como “A Violência”" Em Marquetalia (município localizado no departamento colombiano de Caldas), permaneceu unido durante tal período um grupo atuante, chamado inicialmente de "Bloco Sul” e liderado por Manuel Marulanda Vélez. Em 1966, a partir da mudança de nome e de estratégia ${ }^{2}$, tal grupo passou a constituir oficialmente as FARC (NOGUERA, 2003, p. 2).

Os problemas estruturais, políticos e econômicos do Estado colombiano regaram o ambiente, tornando-o propício para o fortalecimento de grupos que, assim como os idealizadores das FARC, eram alijados socialmente. A Colômbia não gozava de estabilidade econômica satisfatória e, devido principalmente ao contexto da Guerra Fria, era suscetível à influência norte-americana. É por isso que a inspiração do movimento, para além do viés socialista e comunista, deu-se também por meio dos ideais bolivarianos, pois reclamava-se “auto-sustentabilidade e independência frente a intervenções externas” (GUEVARA, 2010, p. 225-226).

A organização primordial das FARC está umbilicalmente relacionada à intensificação dos confrontos violentos e repressivos entre as instituições colombianas de índole liberal, os grupos e as cooperativas agrícolas que, reclamando mais atenção estatal nas causas sociais, inspiravam-se em ideais socialistas e comunistas (GUEVARA, 2010, p. 225). Não foi esse o único grupo guerrilheiro que surgiu no período, tampouco o único que se manteve desde então - destacando-se também nesse contexto o Exército de Libertação Nacional (ELN), segunda maior organização guerrilheira da Colômbia (MARCOS, 2016a), e as Autodefesas Unidas da Colômbia (AUC), que foram o principal grupo paramilitar de extrema-direita da Colômbia, até sua desmobilização em meados de 2005 (INSIGHT CRIME, 2015). Porém, nenhum outro assumiu o contingente das FARC: é o mais numeroso e mais forte em termos militares da história da Colômbia. Não é por outro motivo que,

\footnotetext{
1 “A Violência” teve amplitude tamanha que resultou em cerca de 200.000 mortos em território colombiano (COSOY, 2016).

2 “El Bloque Sur se constituyó oficialmente en las FARC en 1966 durante la Segunda Conferencia Guerrillera donde éste movimiento cambia su estrategia por una ofensiva luchando por la toma del poder” (NOGUERA, 2003, p. 2).
} 
segundo Martha Bottía Noguera, as FARC "se ha convertido en la más grande amenaza para el Estado colombiano y a su vez en el factor más importante en el conflicto interno que vive [el] país” (NOGUERA, 2003, p. 2). Tal desenvolvimento, somado à extensa história de mais de meio século, que colocou o povo sob condições extremas de sofrimento, é o que delineia o pano de fundo no qual se desenvolveu o interesse do governo colombiano em dar início ao processo de negociações para o recente acordo de paz.

\subsection{AS NEGOCIAÇÕES ENTRE O GOVERNO COLOMBIANO E AS FORÇAS ARMADAS REVOLUCIONÁRIAS DA COLÔMBIA: FINALMENTE, O ACORDO DE PAZ}

O êxito logrado pelas FARC, conforme exposto, foi o de maior destaque na história do conflito armado colombiano. Crê-se que tal se deu principalmente devido ao modo como operavam com a multiplicação de suas frentes, tanto de atuação, quanto de financiamento (NOGUERA, 2003, p. 2). O crescimento das frentes de guerrilha das FARC entre os anos de 1978 e $1995^{3}$, bem como das frentes do ELN, pressionou o governo colombiano a tomar uma postura mais ativa perante os grupos, passando a considerar a realização de negociações para a obtenção da paz em seu território (ECHANDÍA, 1999, p. 99-149).

Dentre as medidas tomadas visando ao fim das hostilidades, cabe citar a aprovação da Lei Geral de Anistia (1982) e a derrogação do Estatuto da Seguridade, no governo de Turbay Ayala, que criaram condições favoráveis para que se iniciassem os diálogos entre as FARC e o governo colombiano. Tais medidas resultaram na criação dos Acordos de Cessar-Fogo e Trégua, mais conhecidos como Acordos de Uribe (1984), nos quais as partes se comprometeram a buscar conjuntamente uma saída política para o conflito (UNIVERSITAT DE BARCELONA, s.d.). Esses documentos foram assinados pela Comissão de Paz, Diálogo e Verificação, representantes do governo, e pelo Estado Maior das FARC 4 .

Após a assinatura dos acordos (1984), as FARC ordenaram o cessar-fogo de todas as suas frentes de combate, comando seguido pelo governo colombiano, que deu a mesma ordem a todas as autoridades civis e militares do país. Verificado o fim dos conflitos armados, abriu-se um período de um ano aos integrantes das FARC para que eles pudessem se organizar política, econômica e

\footnotetext{
${ }^{3}$ Nesse período, as frentes de guerrilha das FARC passaram de oito a 65, e as do ELN passaram de três a 35.

${ }^{4}$ As FARC possuem uma organização bem determinada - o Estado-Maior é "mais conhecido como o secretariado, é o órgão superior de direção e de comando das FARC. Os seus acordos, despachos e decisões imperam sobre toda a organização e os seus membros. O secretariado é quem nomeia os líderes de cada bloco, e restringe as áreas que cada bloco deve abranger” (AsFARC, s.d).
} 
socialmente, a fim de que fossem beneficiados pelo disposto na Lei de Anistia ${ }^{5}$. Mesmo após a prorrogação do prazo estabelecido nos Acordos, que foi justificada com base nos altos interesses da nação e na necessidade de se alcançar a paz e o desenvolvimento democrático do país, o assassinato de candidatos presidenciais e de numerosos políticos entre os anos de 1986 e 1990 resultou no fracasso dos diálogos até então estabelecidos (RML/EPD [tam], 2016).

Em 1997, o governo colombiano buscou a retomada das negociações com as FARC, o ELN e as AUC. Essa nova fase do processo de paz, que durou de 1998 a 2002 - período do governo de Andrés Pastrana -, teve sua evolução acompanhada pelo governo de diversos países, assim como por organizações internacionais e setores da sociedade civil colombiana e estrangeira. Como condição para a abertura das conversações, Pastrana ordenou, em 1999, a retirada do Exército colombiano de uma área de 42 mil km², criando uma zona desmilitarizada nos municípios de Mesetas, La Uribe, La Macarena, Villahermosa e San Vicente del Caguán ${ }^{6}$, a ser ocupada pelas FARC a fim de que fosse estabelecido um diálogo com o governo (BBC, 2002). No mesmo ano, Pastrana e o chefe máximo das FARC, Manuel Marulanda Vélez, assinaram o Acordo de Caquetania, que foi ratificado em 2001, de modo a consolidar o esforço conjunto das partes em acabar com o conflito.

Contudo, confrontos entre membros das FARC e de grupos paramilitares levaram ao primeiro congelamento das negociações de paz, situação que apenas se agravou com a realização de atentados pelos grupos armados e pela intenção do governo colombiano em criar uma comissão de verificação para a investigação e apuração das violações de direitos humanos ocorridas na zona desmilitarizada (BBC, 2002). De um lado, os membros da FARC alegavam que essa comissão não teria autoridade para atuar naquela região; de outro, o governo colombiano sofria forte pressão, de grupos políticos e da cúpula militar, para mostrar a capacidade de controle jurídico e político sobre o território desmilitarizado (GRAJALES, 1999).

A despeito dos esforços engendrados pela Organização das Nações Unidas (ONU) e pela Comissão de Países Facilitadores ${ }^{7}$, o agravamento dos conflitos teve como consequência a abolição da zona desmilitarizada (2002) e a sua retomada pelas Forças Militares da Colômbia (BBC, 2002). O término desse processo de diálogo foi oficializado ${ }^{8}$, tornando sem efeito o reconhecimento do caráter político da mencionada organização e de seus representantes. Ademais, autorizou-se a presença militar e judicial na antiga zona desmilitarizada.

\footnotetext{
${ }^{5}$ Lei 35 de 1982 e seus decretos complementares.

${ }^{6}$ Tal foi feito por meio da Resolução 85, de 14 de outubro de 1998.

${ }^{7}$ O grupo era formado pelos governos de Cuba, Espanha, França, Itália, México, Noruega, Suécia, Suíça e Venezuela.

${ }^{8}$ Resoluções 31, 32 e 33, de 2002.
} 
No mesmo ano, Álvaro Uribe, cuja principal proposta pautava-se na política de seguridade democrática, ganhou as eleições presidenciais colombianas, intensificando o combate militar e repudiando qualquer forma de negociação com os grupos armados (POSSO, 2004). Apesar da política mais combativa em relação a esses grupos, o governo colombiano, no período de 2003 a 2006, negociou a rendição de aproximadamente 32 mil paramilitares da AUC, dos quais 4.200 foram julgados por violações de direitos humanos nos anos seguintes. Em junho de 2005, foi aprovada a Lei de Justiça e Paz, concedendo uma ampla anistia aos membros dos esquadrões da morte (RML/EPD [tam], 2016).

Apenas em 2012 houve a efetiva retomada dos diálogos de paz com as FARC, iniciados pelo então presidente Juan Manuel Santos, ex-ministro da defesa do governo de Álvaro Uribe. Marcada pela entrada em vigor da Lei de Vítimas e Restituição de Terras, cujo objetivo era a compensação dos deslocados pelos combates, a negociação teve início em agosto do mesmo ano, tendo resultado na criação do “Acuerdo general para la terminación del conflicto y la construcción de una paz estable y duradera” (EL PAÍS, 2012). Dentre os pontos de discussão do acordo podem-se destacar: a realização de uma política de reforma agrária integral, envolvendo a criação de terras agrárias em lugares que constituem zonas de reserva florestais, terrenos baldios e latifúndios improdutivos; o direito à participação política dos membros das FARC; o final do conflito, processo a ser iniciado pela entrega das armas por parte dos combatentes, visando sua integração à sociedade civil; a solução do problema das drogas ilícitas, por meio da erradicação manual das drogas e interrupção do cultivo das plantas que são utilizadas em sua produção; o auxílio para a identificação das vítimas do conflito; a utilização de um mecanismo específico para referendar os acordos firmados entre as partes. Cabe dizer que, um ano após o início das negociações, as FARC reconheceram, pela primeira vez, sua responsabilidade pelas vítimas do conflito armado (EL UNIVERSAL, 2016).

Como esperado, diversas foram as reações ao acordo firmado entre o governo de Juan Manuel Santos e as FARC. Setores políticos, como o Partido Conservador e o Partido CentroDemocrático (fundado pelo antigo presidente Álvaro Uribe), mostraram imediatamente seu descontentamento com os termos do acordo, alegando que eles permitiriam que os acusados pelos graves delitos cometidos durante o conflito fossem isentos de qualquer responsabilidade (VANGUARDIA, 2013). Por outro lado, o Partido Verde, o Movimento Progressista, os partidos liberais e setores da sociedade civil expressaram seu apoio aos diálogos de paz, demonstrando o interesse no fim do conflito (CARACOL, 2013; POSADA, 2012; EL INFORMADOR, 2012).

O chefe do Ministério Público, Alejandro Ordóñez Maldonado, alegou a inconstitucionalidade dos termos do acordo, uma vez que eles tornariam impossível a garantia dos 
direitos à verdade, à justiça e à reparação das vítimas, afetando os processos judiciais relacionados aos máximos comandantes dos grupos armados ilegais e colocando um véu de impunidade sobre os responsáveis (SEGURA, 2013). O procurador comparou o processo colombiano com as situações enfrentadas pelos governos do Congo, Camboja, Serra Leoa e da antiga Iugoslávia, afirmando que os termos do acordo viabilizariam apenas a investigação dos crimes contra a humanidade, dos crimes de guerra e dos genocídios, afastando a responsabilização por demais condutas criminosas (COLÔMBIA, 2013).

Internacionalmente, as reações aos diálogos de paz apresentaram-se mais favoráveis, contando com o apoio de diversos países (EL TIEMPO, 2016), incluindo os cinco membros permanentes do Conselho de Segurança da $\mathrm{ONU}^{9}$, e organizações internacionais, entre elas a ONU e a Organização dos Estados Americanos (OEA) (EL PAÍS, 2016; CENTRO DE NOTICIAS ONU, 2016).

Enquanto isso, os diálogos do governo com as FARC foram interrompidos e reabertos reiteradamente devido às ações militares de ambos os lados. Apenas com o cessar-fogo unilateral, anunciado pelas FARC em dezembro de 2015, as negociações foram retomadas. Dentre os acordos firmados no período, destacam-se os que estabeleceram a criação de uma Comissão da Verdade, a busca conjunta pelas mais de 25 mil pessoas dadas como desaparecidas durante o conflito e a estruturação de um sistema integral para a reparação, justiça, verdade e garantias de não repetição (EL UNIVERSAL, 2016). Nos meses seguintes, as partes acordaram pela adoção de um cessar-fogo bilateral e definitivo, e pela celebração de um plebiscito como mecanismo para referendar o acordo final.

No dia 24 de agosto de 2016, o governo colombiano e as FARC selaram o Acuerdo Final para la Terminación del Conflicto y la Construcción de Una Paz Estable y Duradera, para encerramento das negociações de paz, que foi assinado pelos representantes de cada um dos grupos. Entre os pontos levantados no acordo final, destacam-se: o fim das FARC como um movimento armado; a entrega das armas pelos membros do grupo; a reparação às vítimas; a luta mais eficaz contra as organizações criminosas e tráfico de drogas, o fortalecimento das instituições democráticas e estaduais da Colômbia e o fim do sequestro, extorsão e hostilidade contra a população e o poder público (PORTAL DO PLANALTO, 2016).

\footnotetext{
${ }^{9}$ São membros permanentes do Conselho de Segurança da ONU: Estados Unidos, França, Rússia, Reino Unido e China. 
Em dois de outubro do mesmo ano o plebiscito foi realizado, a fim de que a população da Colômbia decidisse sobre a aceitação ou não dos termos do acordo assinado ${ }^{10}$. Com uma grande taxa de abstenção (62,59\% dos eleitores), o resultado da consulta demonstrou a insatisfação da população, sendo o acordo de paz rejeitado por 50,22\% dos votantes (BBC, 2016b). A decisão impediu que as medidas negociadas para pôr fim aos mais de 50 anos do conflito armado fossem postas em prática (RML/EPD [tam], 2016).

O governo colombiano e o comandante chefe das FARC, Timoleón Jiménez (Timochenko), manifestaram seu descontentamento com o resultado do plebiscito, e alegaram que continuarão respeitando os termos dos acordos firmados antes da realização do plebiscito e empregando esforços para alcançar a paz (LAFUENTE, 2016a).

\section{O DIREITO INTERNACIONAL DOS DIREITOS HUMANOS E O DIREITO INTERNACIONAL HUMANITÁRIO: DISTINÇÕES E SEMELHANÇAS ANTE O CASO COLOMBIANO}

O fenômeno das guerras sempre ocupou posição central no desenrolar da história (BORGES, 2006, p. 1). Com a crescente necessidade de justificação do uso desse recurso pelos Estados é que inicialmente surgiu o DIH (FERNANDES, 2006, p. 45-54). Assim é que, outrora, a preocupação em relação ao tema dava-se primordialmente no âmbito dos Estados, quando da existência de conflitos e guerras que envolviam duas ou mais soberanias. O intuito primeiro era a salvaguarda das vítimas dos conflitos, mas as normas tinham datas pré-fixadas de vigência.

Atualmente, após reconhecer a necessidade de proteção não mais de maneira pontual, e sim embasada em documentos sólidos e convencionais (GUERRA, 2008, p. 76-80), o DIH adotou como principal fonte normativa as Convenções de Genebra de 1949, produto da maior manifestação de violência experimentada na contemporaneidade ${ }^{11}$ e principal instrumento pacificador do DIH (FERNANDES, 2006, p. 80), que manejam também o período posterior aos conflitos armados (CICCO FILHO, 2008, p. 107).

A noção de conflito armado foi, em certa medida, adotada em substituição à noção de guerra. Segundo Leonardo Estrela Borges, isso ocorreu devido ao próprio “dinamismo da vida social e, principalmente, pelo surgimento de novas formas de conflito armado”. Isso porque, enquanto a noção

\footnotetext{
${ }^{10}$ Na cédula de votação constava a pergunta: "Você apoia o Acordo Final para o fim do conflito e construção de uma paz estável e duradoura?”, a qual deveria ser respondida com “Sim” ou “Não”.

11 Jean Marcel Fernandes refere-se, aqui, ao holocausto (FERNANDES, 2006).
} 
de guerra tem conotação de um conflito existente entre dois Estados soberanos, a noção de conflitos armados admite atores não estatais como protagonistas (BORGES, 2006, p. 8-13).

No caso colombiano, conforme explanado na primeira sessão deste trabalho, os embates não se deram entre dois países, e sim entre o Estado colombiano e uma série de grupos guerrilheiros e paramilitares. Dessarte, fosse ainda utilizado o critério embasado no conceito de guerra para a aplicação do DIH, tal se tornaria inviável, tornando a situação alheia às diretrizes desse ramo do Direito.

Embora possa soar conflitante a intenção de impor regras de humanidade quando de uma circunstância tão degradante quanto a de uma guerra ou conflito armado, é imperioso que o Direito não ignore a necessidade de amparo àqueles que são vitimados por essas situações. É com esse fito que atua o DIH. Sua intenção primeira não é “fazer da guerra uma situação humana” (BORGES, 2006, p. 3), tampouco fornecer argumentos para que os beligerantes declarem "sua causa como sendo uma guerra justa” (BORGES, 2006, p. 3). É, antes, estar apto a oferecer normas capazes de regulamentar o direito de guerra - jus in bello (FERNANDES, 2006, p. 45-54) -, evitando que os confrontos se degenerem em barbáries absolutas (BORGES, 2006, p. 5).

Em termos históricos, as origens do DIH remontam a tempos bastante remotos (FERNANDES, 2006, p. 23-29). Desde meados do século passado, porém, com a internacionalização das normas de direitos humanos (PIOVESAN, 2015b, p. 196), surgiram alguns problemas no que tange à relação entre esses dois segmentos do Direito (SWINARSKI, 1990, p. 87-94).

Para além de divergências relacionadas ao tempo histórico de seu surgimento ${ }^{12}$, o DIH e o DIDH afastam-se também no que diz respeito à organização e funcionamento de suas instituições, que são autônomas. Enquanto este conta com os sistemas regionais e global, aquele tem no Comitê Internacional da Cruz Vermelha (CICV) seu principal pilar e ator de difusão de sua normativa (VALLADARES, 2008, p. 26-29).

Há diferenças que residem, ainda, no âmbito de aplicação de cada um deles (SWINARSKI, 1996, p. 22-25), sendo essas as mais proeminentes (BORGES, 2006, p. 39). Em termos de aplicação material, temporal e local, o DIH aplica-se estritamente quando há conflitos armados, nas localidades onde eles se desenvolvem e que são atingidas pelas hostilidades. As normas de DIDH, ao revés, são aplicadas em qualquer tempo e local, em homenagem ao princípio da universalidade (PIOVESAN, 2015a, p. 49). Há, contudo, para o DIDH, possibilidades de suspensão de sua normativa em virtude

\footnotetext{
12 O DIH tem gênese longínqua em termos históricos (BORGES, 2006, p. 38), ao passo que o DIDH tem raízes no pósSegunda-Guerra (PIOVESAN, 2015b, p. 196).
} 
de dificuldade de ordem prática em situações belicosas ${ }^{13}$. As normas de DIH, por sua vez, não admitem qualquer sorte de derrogação (BORGES, 2006, p. 39).

Ademais, com relação à aplicação pessoal, o DIDH não abre espaço para qualquer distinção entre seus destinatários, ao passo que o DIH tem um “critério restritivo” (BORGES, 2006, p. 39), pois dirige-se especificamente àqueles afetados pelos conflitos armados (SWINARSKI, 1990, p. 8994). Outrossim, insta salientar que, enquanto o DIDH pode ser identificado como um "direito promocional da pessoa humana” (SWINARSKI, 1990, p. 90), o DIH é, antes de tudo, "um direito de sobrevivência”, que busca conservar o indivíduo ante a barbárie, e não prover a ele mais espaço para que conquiste melhores condições de vida digna (SWINARSKI, 1990, p. 90).

As diferenças, porém, não querem significar a primazia de um sobre o outro, tampouco os torna excludentes entre si. Vale dizer, é possível (e não muito excepcional) que haja a atuação de algum sistema de direitos humanos no mesmo território e tempo de um conflito armado - sujeito, portanto, à aplicação das normas de DIH.

Não é outro o caso do conflito armado colombiano. Desde meados do século XX, durante o período de conflito armado, há diversos casos que se desenvolveram sob o contexto do conflito armado entre Estado, guerrilhas e grupos paramilitares, que foram submetidos à jurisdição da Corte Interamericana de Direitos Humanos ${ }^{14,15}$. Concomitantemente, o CICV tem atuado de maneira ampla no país (CONSILIUM, 2009, p. 3-4; VALLADARES, 2008, p. 32), reforçando a ideia de que a ingerência do Sistema Interamericano de Direitos Humanos não impede a aplicação das normas do DIH (VALLADARES, 2008, p. 41-42).

Isso ocorre, sobretudo, devido ao fato que, mesmo com as previsões de possibilidade de derrogação, por mais extrema que seja a situação, o DIDH possui um núcleo duro inderrogável

\footnotetext{
${ }^{13}$ Vide: Convenção Europeia dos Direitos Humanos, artigo 15; Convenção Americana de Direitos Humanos, artigo 27; Pacto Internacional sobre Direitos Civis e Políticos, artigo 4. Não há que se excluir, contudo, a existência de normas integrantes do núcleo duro dos Direitos Humanos que, por sua natureza, mantêm-se sempre em plena vigência (CANÇADO TRINDADE, 1997, p. 32-33).

${ }^{14}$ Vide: CORTE INTERAMERICANA DE DIREITOS HUMANOS. Caso 19 Comerciantes vs. Colômbia. Mérito, Reparações e Custas. Sentença de 5 de julho de 2004. Série C, nº 109; Id. Caso Las Palmeras vs. Colômbia. Mérito. Sentença de 6 de dezembro de 2001. Série C, nº 90; Id. Caso do Massacre de Mapiripán vs. Colômbia. Mérito. Sentença de 15 de setembro de 2005. Série C, nº 134; Id. Caso Massacre de Santo Domingo vs. Colômbia. Exceções preliminares, Mérito, Reparações e Custas. Sentença de 30 de novembro de 2012. Série C, $\mathrm{n}^{\circ}$ 259; Id. Caso das comunidades afrodescendentes deslocadas da Bacia do Rio Cacarica (Operação Gênesis) vs. Colômbia. Excepciones Preliminares, Mérito, Reparações e Custas. Sentença de 20 de novembro de 2013. Série C No. 270; Id. Caso do Massacre de Pueblo Bello vs. Colômbia. Sentença de 31 de janeiro de 2006. Série C, $\mathrm{n}^{\circ} 140$.

${ }^{15}$ Não é escopo deste trabalho esgotar a análise dos casos submetidos à Corte Interamericana de Direitos Humanos em face da Colômbia durante o período de (e em conexão com) conflitos armados. Por essa razão, os casos aqui citados para dar solidez à afirmação têm caráter meramente exemplificativo, sendo que sua escolha foi assim feita por representarem emblematicamente a relação entre o Direito Internacional Humanitário e o regime interamericano de proteção aos Direitos Humanos.
} 
(CANOTILHO, 2003, p. 1370). Esse núcleo é composto por direitos elementares que geram obrigações erga omnes, aplicáveis até mesmo à margem do direito convencional (RAMOS, 2002, p. 54). Isso faz do DIDH um ponto complementar ao DIH e vice-versa (CORTE INTERAMERICANA DE DIREITOS HUMANOS, Voto em Separado Antonio Augusto Cançado Trindade, 2000, par. 34).

Dessarte, diante de uma visão de complementaridade (BORGES, 2006, p. 37; VALLADARES, 2008, p. 42; SWINARSKI, 1996, p. 22-24) entre esses dois ramos, há entre eles conexão estreita no que tange seu norte: a proteção da dignidade da pessoa humana como elemento central de suas preocupações (BORGES, 2006, p. 37-38; SWINARSKI, 1990, p. 91-94). Diante disso, bem como tendo em mente a impossibilidade de derrogação de normas cogentes de Direitos Humanos (CANÇADO TRINDADE, 1997, p. 32-33), as normas de ambos vão ao encontro umas das outras, tornando-se mutuamente aplicáveis em tempos de conflitos armados (SWINARSKI, 1990, p. 91-94).

\subsection{O CONFLITO ARMADO NA COLÔMBIA SEGUNDO O DIREITO INTERNACIONAL HUMANITÁRIO}

Como visto, o DIH, aplicável aos conflitos armados internacionais e nacionais (BUERGENTHAL, 1988, p. 190), pode ser caracterizado como uma ampliação do jus in bello, voltada para o tratamento, em guerra, tanto dos combatentes quanto dos não combatentes. A necessária diferenciação entre as duas categorias de conflito é pautada na regulamentação jurídica, em âmbito internacional, tendo como enfoque a regulamentação do emprego da violência (LAFER, 2003, p. XXIV-XXV), impedindo que as partes envolvidas em um conflito utilizem os métodos de guerra de sua escolha (BETTATI, 2000, p. 24).

Ocorre que, embora o DIH tenha como foco a limitação dos efeitos dos conflitos armados, ele, por si mesmo, não apresenta definições claras das situações que se enquadram em seu campo material de aplicação (PEJIC, 2011). Dessa forma, torna-se necessária a análise a contento dos documentos internacionais que regem a matéria.

Entre os tratados internacionais que se dedicam ao tema, cabe citar as Convenções de Genebra de 1949, que adotaram uma visão mais objetiva dos conflitos armados. A expansão desse conceito deu-se apenas em 1977, com a adoção do Protocolo Adicional I e do Protocolo Adicional II, que buscou tratar especificamente da questão dos conflitos armados internos (VITÉ, 2009, p. 74).

Sob o ponto de vista jurídico, os conflitos armados regidos pelo DIH podem ser internacionais (CAI) ou não internacionais (CANI). Cabe dizer que essa definição não é estática, de 
modo que uma situação pode passar de uma categoria a outra, a depender dos fatos vigentes no momento, como, por exemplo, nos conflitos internos internacionalizados.

Os CAI, especificamente, encontram previsão no artigo $2^{\circ}$ comum às Convenções de Genebra, que os define como aqueles em que se enfrentam as “Altas Partes Contratantes”, sendo estas os Estados, não importando a intensidade do conflito (GASSER, 1993, p. 510-511). Embora o artigo fale em “Altas Partes Contratantes”, esse requisito acaba perdendo sua importância prática, pois as quatro Convenções de Genebra são universalmente ratificadas (COMITÊ INTERNACIONAL DA CRUZ VERMELHA, 2008).

Ressalte-se que as normas relevantes do DIH podem ser aplicáveis mesmo na ausência de hostilidades abertas, declaração formal de guerra ou reconhecimento da situação (DAVID, 2002, p. 109). Releva-se, portanto, a amplitude da contenda, podendo esta se configurar a partir de um simples incidente fronteiriço ou escaramuça.

O Protocolo Adicional I, por sua vez, traz uma ampliação à definição dos CAI, abrangendo situações que envolvam o enfrentamento de povos contra a dominação colonial, ocupação estrangeira ou regimes racistas, no exercício de seu direito à autodeterminação.

Com relação aos CANI, a Convenção de Genebra de 1949, em seu artigo $3^{\circ}$ comum, defineos como sendo aqueles que compreendem o envolvimento de um ou mais grupos armados não governamentais. De acordo com a situação do país, as hostilidades podem existir entre forças armadas governamentais e grupos armados dissidentes, ou apenas entre esses grupos (COMITÊ INTERNACIONAL DA CRUZ VERMELHA, 2008). O Protocolo Adicional II restringe essa definição em seu artigo 1(1), fazendo menção à necessidade de controle territorial, e traz limitações à sua aplicação no parágrafo 2 do mesmo artigo, excluindo do seu âmbito de incidência as situações de tensão e de perturbação interna, tais como motins, atos de violência isolados e esporádicos e demais atos análogos, que não devem ser considerados conflitos armados.

Em decisões de Tribunais Internacionais, como, por exemplo, nos casos The Prosecutor $v$. Dusko Tadic (TRIBUNAL PENAL INTERNACIONAL, 1995, par. 70) e The Prosecutor v. Fatmir Limaj (TRIBUNAL PENAL INTERNACIONAL, 2005, par. 84), foram estabelecidos critérios para a definição dos CANI, de modo a diferenciá-los de distúrbios internos, tensões, tumultos ou atos de banditismo.

Em primeiro lugar, entende-se que as hostilidades devem atingir um nível mínimo de intensidade, a ser determinado de acordo com a duração e a gravidade dos conflitos armados, o número de vítimas, o número de combatentes e tropas presentes, os tipos de armamentos empregados, o tipo de forças governamentais envolvidas e o alcance dos danos causados pelos combatentes 
(LAWAND, 2012). Por fim, analisa-se o nível de organização do grupo armado, que deverá ser avaliado com base na existência de uma cadeia de comando, na habilidade de planejar e executar operações militares coordenadas, na capacidade de transmitir e executar ordens e na competência para recrutar, treinar e equipar novos combatentes (LAWAND, 2012).

Ainda, cabe destacar que, como dito anteriormente, os conflitos armados podem evoluir de uma categoria para a outra, dependendo dos eventos ocorridos. Como exemplo de um conflito armado internacionalizado, têm-se os casos em que há uma intervenção externa para combater um conflito interno previamente existente, como quando um país estrangeiro manda tropas para apoiar um movimento de oposição ao governo local (VITÉ, 2009, p. 71). Nessas circunstâncias, torna-se essencial determinar o nível de controle sobre o grupo armado, a fim de possibilitar a classificação do conflito interno como internacional.

No caso colombiano, tendo em vista o fato de os embates terem ocorrido entre as forças armadas do Estado e grupos armados dissidentes, vê-se excluída a possibilidade de caracterização como conflito armado de natureza internacional, uma vez que não se trata de um conflito travado entre dois ou mais Estados (PEJIC, 2011, p. 189-225). Caracteriza-se, dessa maneira, como um CANI, de caráter prolongado, e que deve ser regido pelas normas de DIH.

\section{O PAPEL DO COMITÊ INTERNACIONAL DA CRUZ VERMELHA (CICV) NO PROCESSO DE PAZ COLOMBIANO}

A aplicabilidade do DIH é viabilizada por “agentes aplicadores” (FERNANDES, 2006, p. 77), sendo um deles o CICV, principal órgão do Movimento Internacional da Cruz Vermelha e do Crescente Vermelho (FERNANDES, 2006, p. 77-81).

Desde a sua fundação (1863), o CICV atua de maneira ativa na promoção e garantia da paz, sendo que sua própria criação tem papel de protagonismo na consolidação do DIH (FERNANDES, 2006, p. 78) e seu trabalho é desenvolvido com espírito de vanguarda para a aplicação da normativa internacional relacionada aos conflitos armados (CROCE ROSSA ITALIANA, 2008).

Na América Latina, seu desempenho tem refletido o incentivo e comprometimento das autoridades nacionais para com a ratificação de documentos internacionais sobre conflitos armados (CICCO FILHO, 2008, p. 111). Sobre o tema, Abel Peña, Presidente do Comitê Regional Interamericano da Cruz Vermelha, assevera que a ajuda humanitária no continente é desafiada pela pobreza, desigualdade social e vulnerabilidade das populações (CICCO FILHO, 2008, p. 112). 
No contexto de conflito armado colombiano, o trabalho do CICV é o sexto maior do mundo. Sua atuação é bastante vasta, mas os principais pontos podem ser indicados como: visita aos aprisionados; visitação de militares e policiais capturados; eliminação de minas antipessoais; auxílio às vítimas e integração com demais atores que se dedicam a causas conexas. Não é demais citar que, para além do trabalho desenvolvido com as vítimas do conflito armado, o CICV tem também propósitos preventivos no território colombiano, trabalhando, para tanto, em conjunto com a Cruz Vermelha local (CICCO FILHO, 2008, p. 112).

Para a sua atuação efetiva, é de suma importância seu reconhecimento por parte dos atores envolvidos nos conflitos, que, ao fim e ao cabo, emprestam-lhe legitimidade como agente de promoção do DIH para além do âmbito legal (CROCE ROSSA ITALIANA, 2017). Em 2015, durante as negociações para o acordo especial que regraria a busca por pessoas desaparecidas em razão do conflito armado colombiano (LAFUENTE, 2015), a atuação do CICV deu-se por meio de uma solicitação feita em comum acordo por ambas as partes - o governo e as FARC.

Normalmente fazem parte dos acordos especiais as partes que estão diretamente envolvidas no conflito - como no caso em questão, em que tais partes foram um grupo armado não estatal e o governo. Em alguns casos, porém, para além das partes, é possível haver solicitação da "participação de um terceiro para implementar os acordos, como uma organização humanitária, sem que seja parte de tais acordos” (COMITÊ INTERNACIONAL DA CRUZ VERMELHA, 2016b).

A natureza desses acordos especiais está impressa no Direito Internacional, pois são institutos que viabilizam que as partes em um conflito interno negociem obrigações mais amplas ou detalhadas para além daquelas previstas pelas Convenções de Genebra de 1949, no intuito de tornar mais efetiva a proteção da população civil (COMITÊ INTERNACIONAL DA CRUZ VERMELHA, 2016b).

É certo que, em um primeiro momento, no processo de negociação da paz, as normas de DIH somam-se ao ordenamento jurídico interno para pautar os termos negociados. Contudo, situação de caráter delicado e político que é, a negociação entre as partes envolvidas requer, muitas vezes, a elaboração de acordos especiais com o fito de "ampliar os seus deveres com fins humanitários ou definir mecanismos para implementar” obrigações (COMITÊ INTERNACIONAL DA CRUZ VERMELHA, 2016b).

A possibilidade de subscrição dos acordos especiais tem previsão no artigo $3^{\circ}$ comum às Convenções de Genebra, sendo que, em 1952, o Comitê Internacional da Cruz Vermelha, em seus comentários a essa norma (COMITÊ INTERNACIONAL DA CRUZ VERMELHA, s.d.a), sugeriu a possibilidade de que os acordos de paz sejam firmados na condição de acordos especiais - sugestão 
que foi reafirmada em março de 2016 (COMITÊ INTERNACIONAL DA CRUZ VERMELHA, 2016b).

Sobre o tema, o CICV esclarece, ainda, que a assinatura de um acordo especial não tem o escopo de afetar "o status jurídico dos grupos armados não estatais, nem tampouco implica um reconhecimento de beligerância” (COMITÊ INTERNACIONAL DA CRUZ VERMELHA, 2016b), mas atua apenas como catalisador de um processo que, de outro modo, seria inviabilizado ou, quando menos, dificultado de modo extremo.

Devido à inexistência de um procedimento expressamente detalhado para que um acordo de paz se transforme em um acordo especial, tanto no Direito Internacional quanto no Direito interno, não raro as partes veem-se na obrigação de estabelecer suas próprias regras. No caso da Colômbia, as partes do conflito armado no país (o governo e as FARC) optaram por acordar um mecanismo sui generis para esse fim, embasando-o em três principais pilares: (a) a tramitação no Congresso, com posterior revisão, pela Corte Constitucional, de duas emendas da Constituição, bem como de uma lei de sanção do acordo final; (b) o depósito do acordo final propriamente dito, categorizado como um acordo especial perante o Conselho Federal Suíço e (c) uma declaração de caráter unilateral do Presidente da República diante do Secretário-Geral das Nações Unidas, a fim de reconhecer o acordo final como sendo especial e de caráter cogente (COMITÊ INTERNACIONAL DA CRUZ VERMELHA, 2016b).

Desde o anúncio do cessar-fogo em junho de 2016 (MARCOS, 2016b), o CICV posicionouse de maneira otimista em relação às negociações, lembrando o fim das ações armadas como fator de contribuição "para uma maior eficácia na implementação das medidas humanitárias acordadas no marco do processo de paz” (COMITÊ INTERNACIONAL DA CRUZ VERMELHA, 2016a).

Assim que o acordo de paz foi anunciado, novamente assumiu postura de satisfação, chamando atenção, ainda, para a necessidade de dar continuidade aos seus trabalhos, uma vez que a assinatura do acordo não bastaria como forma de solução de toda a situação hostil que se instaurou no país como consequência do conflito histórico (COMITÊ INTERNACIONAL DA CRUZ VERMELHA, 2016c).

Depois de anos de negociações, o cessar-fogo bilateral e definitivo foi consolidado no extenso acordo de paz (COLÔMBIA, 2016), apreciado pela população em sede de plebiscito, cujo resultado foi negativo à aprovação dos termos atuais do acordo (LAFUENTE, 2016b). Apesar da postura otimista assumida pelo CICV e também por diversas outras organizações que atuam na 
proteção dos Direitos Humanos ${ }^{16}$, é imperioso perceber que a firmação de um acordo de paz não significa o fim dos problemas de viés humanitário surgidos na Colômbia em decorrência dos conflitos. O próprio CICV chama atenção para o fato de que, mesmo que comemorado, o acordo de paz não é o resultado final. É, antes, um ponto de partida para desafios vindouros que devem continuar a ser enfrentados.

É com expertise que Christoph Harnisch, chefe da delegação do CICV na Colômbia em 2015, lembra que:

Para as famílias das cem mil pessoas desaparecidas no país, não haverá paz até que tenham resposta à pergunta que marca as suas vidas: “Onde está o meu ente querido?” Para os que vivem nas áreas contaminadas por artefatos explosivos, a paz chegará quando puderem cultivar, ir à escola ou simplesmente passear sem medo de perder uma extremidade do corpo ou a própria vida. Para os menores que vivem separados dos seus entes queridos em virtude do conflito armado, a paz virá quando puderem abraçá-los de novo e recomeçar, assim, as suas vidas (COMITÊ INTERNACIONAL DA CRUZ VERMELHA, 2015).

Outra preocupação expressada pelo próprio CICV em relação ao acordo de paz, antes mesmo de ele ser definitivamente firmado entre as FARC e o governo, diz respeito aos bandos criminosos grupos apartados dos guerrilheiros cuja atuação é tão impactante no cenário humanitário quanto os conflitos armados. Segundo Jordi Raich, então chefe da delegação do CICV na Colômbia, "nos paradoxos da desgraça, a consequência mais imediata de um acordo de paz com as FARC e o ELN poderia ser a ampliação da área de atuação e da violência desses bandos” (RAICH, 2014).

José Miguel Vivanco, Diretor Executivo da divisão das Américas da Human Rights Watch, também é crítico de alguns pontos firmados no acordo, especulando os motivos que poderiam justificar a escolha do “não” pela população colombiana em relação a tal acordo. Para Vivanco, apesar de o acordo materializar uma oportunidade única de coibir o sofrimento imediato da população, o componente da justiça não veio a contento. Isso porque o risco de perpetuação das violações de direitos humanos é patente diante do excesso de benefícios ${ }^{17}$ concedidos às partes envolvidas que, segundo ele, terão a certeza da impunidade penal em relação aos crimes atrozes cometidos (VIVANCO, 2016).

Contrariamente, Nélson Camilo Sánchez, coordenador de pesquisa da organização colombiana DeJusticia (Centro de Estudios de Derecho, Justicia y Sociedad), afirma que o acordo

\footnotetext{
${ }^{16}$ Um documento de apoio ao acordo de paz foi assinado por 75 organizações de direitos humanos de vários lugares do mundo. O documento pode ser consultado em: http://www.humanas.cl/?p=15555.

17 “O acordo prevê a criação de um tribunal especial para julgar os crimes cometidos por guerrilheiros no conflito. Embora preveja condenação para crimes hediondos, como tortura, sequestro e estupro, as penas serão cumpridas em espaços de 'movimentação limitada e vigilância', em vez de cadeias comuns. Os magistrados ainda podem anistiar tais crimes, se entenderem que houve ‘conotação política'. As cortes se dissolverão numa década e só aceitarão acusações nos primeiros anos” (CÔRTES, 2016).
} 
de paz entre o governo colombiano e as FARC é gérmen de um "processo de fortalecimento da democracia” (SÁNCHEZ, 2016), assegurando o direito de quase oito milhões de vítimas do conflito (BBC, 2016a).

Para Sánchez, as grandes virtudes do acordo são três: (a) o abarcamento de questões de mais de uma natureza, incluindo tanto as causas como as consequências do conflito, com especial loci para a transição da guerra à paz e os processos de desarmamento, desmobilização e reintegração - e, por isso, demonstrando real intenção de acabar com o conflito; (b) a inclusão de diferentes atores no processo de paz e de prestação de contas, elencando benefícios e compromissos a serem assumidos tanto pelos grupos armados como pelo Estado; e, por fim, (c) a consciência da obrigatoriedade do Direito Internacional, elevando a preocupação com as vítimas ao ponto central da implementação dos compromissos (SÁNCHEZ, 2016).

Além disso, lembra também que, por ser uma bandeira histórica das guerrilhas, a questão da desigualdade na posse e distribuição de terras reclama solução que se aportou como base para uma paz estável e duradoura. Reconhecendo o desafio posto à frente, considera que o acordo de paz tem potencial para enfrentá-lo, já que é permeado por um “forte componente de implementação territorial, [...] uma política de desenvolvimento rural integral, [...] [e pela] continuação e fortalecimento da justiça rural” (SÁNCHEZ, 2016).

Se é certo que a intenção de alcançar uma paz estável e durável é expectativa compartilhada pelo povo colombiano, não há que olvidar que a assinatura do acordo de paz foi só o começo de um longo caminho. O cessar-fogo e a entrega das armas pelos grupos armados, por mais importante que sejam, são apenas os primeiros passos. Passos, estes, que não são respostas, tampouco alternativas, para as pessoas que anseiam por justiça, reparações e garantias de não repetição (VERMELHO, 2014).

Rafael Duarte Villa e Manuela Trindade Viana com razão lembram que, ao mesmo tempo que o conflito armado colombiano nasceu de uma vertente de desigualdades sociais e econômicas e de exclusão política, a sua perpetuação ao longo da história contribuiu significativamente para o agravamento de problemas da mesma natureza: gerou “mais de 37 mil mortos de 1990 a 2002 (INTERNATIONAL CRISIS GROUP, 2007) e mais de 3,5 milhões de deslocados internos entre 1999 e 2010” (VIANA; VILLA, 2012, p. 405).

Ademais,

O conflito contribui, entre outros fatores, para o desvio de recursos do Estado para a área de segurança e para o sentimento permanente de insegurança na população, além de criar 
exigências emergenciais de políticas que deem conta dos enormes custos sociais decorrentes do deslocamento dessa população (VIANA; VILLA, 2012, p. 405).

É por isso que, reconhecendo que os desafios postos estão mantidos e, quiçá, ainda maiores daqui para frente, o CICV reconhece a necessidade de manutenção de seus compromissos para com o povo colombiano. Como principais desafios, elenca a contínua busca por desaparecidos, a tratativa das famílias isoladas em decorrência das minas antipessoal, o enfrentamento da crise humanitária nos presídios e da violência generalizada (COMITÊ INTERNACIONAL DA CRUZ VERMELHA, s.d.b). Lembra o CICV que seu trabalho se dá "en países afectados por conflictos armados y otras situaciones de violencia que ponen en riesgo a la población civil y son un reto para la conciencia de la humanidad. Ambos contextos aún están presentes en Colombia” (COMITÊ INTERNACIONAL DA CRUZ VERMELHA, 2016d).

É por isso que encarar o acordo de paz como verdadeiro ponto de partida parece ser a postura mais coerente, pois revela consciência acerca dos problemas perpetuados, sem negar que as negociações para pôr fim ao conflito, de fato, interessam a todos os atores nele envolvidos. Diante disso, será necessário tanto habilidade política do governo colombiano, como contínua participação de organismos internacionais (CÔRTES, 2016).

Nesse cenário, é de suma importância o papel assumido pelo DIH, que continua tendo sua aplicação viabilizada pela atuação do CICV, cujo papel é vital em uma realidade em que ainda persistem as consequências da violência.

\section{CONSIDERAÇÕES FINAIS}

Como visto, se em um primeiro momento o objetivo do DIH é servir como uma barreira aos conflitos armados, quando esses já estão em andamento surge a necessidade de preservação da humanidade perante a realidade da guerra. Mostra-se, dessa maneira, que embora a proposta desse ramo do Direito seja a mitigação do sofrimento humano, a "humanização” da guerra, em momento algum pretende-se normalizar ou banalizar a crueldade com que são tratados os que se encontram em posição mais vulnerável diante de uma situação de constante tensão e hostilidade.

A gravidade da situação na Colômbia é ressaltada pela simples análise dos dados do confronto entre as forças armadas colombianas e os grupos armados dissidentes. De acordo com dados do relatório Basta Já! Colômbia: Memórias de Guerra e Dignidade, apresentado no ano de 2013 pelo Centro Nacional de Memória Histórica, foram mortas, em pouco mais de meio século de conflito, aproximadamente 220 mil pessoas, sendo que destas, cerca de 170 mil eram civis. 
A despeito dos esforços do governo colombiano, que remontam à década de 1980, e que, após reiteradas tentativas infrutíferas, ganharam força com os diálogos de paz iniciados, no ano de 2012, pelo presidente Juan Manuel Santos, o conflito ainda vigora. A surpreendente resposta negativa ao plebiscito realizado ao final de 2016, o qual buscava a aprovação, por parte da população colombiana, do Acuerdo Final para la Terminación del Conflicto y la Construcción de Una Paz Estable y Duradera, demonstrou um descontentamento geral com os termos do acordo de paz, em grande parte devido ao receio de que ele servisse como um véu de impunidade a ser colocado sobre a cabeça dos responsáveis pelas graves violações perpetradas durante o conflito.

Embora o presidente Juan Manuel Santos e o comandante chefe das FARC, Timochenko, tenham afirmado que continuarão a investir esforços para alcançar a paz no território colombiano, muito ainda deve ser feito para que o conflito tenha um desfecho aceitável para as partes envolvidas. Nesse contexto, inserem-se as disposições do DIH e as atividades das organizações internacionais, das quais se destaca o CICV, de modo que a garantia dos direitos à verdade, à justiça e à reparação das vítimas seja preservada.

\section{REFERÊNCIAS}

AMIN, Mônica Concha. Alguns efeitos das atividades dos participantes no conflito armado na Colômbia sob a ótica de externalidades. Montes Claros: Revista Unimontes Científica, v. 6, n. 2, jul./dez. 2004.

AsFARC. Estrutura das FARC. AsFARC, s.l., s.d. Disponível em: http://www.asfarc.com. Acesso em: 1 fev. 2017.

BBC. Cronología del Processo de Paz. BBC World Service, Londres, fev. 2002. Disponível em: <http://news.bbc.co.uk>. Acesso em: 1 fev. 2017.

BBC. Em Números: prestes a acabar, conflito colombiano é o mais duradouro do continente. BBC Brasil, s.l., 26 set. 2016a. Disponível em: <https:/goo.gl/7D7Lo8>. Acesso em: 1 fev. 2017.

BBC. Em votação apertada, colombianos rejeitam acordo de paz com as Farc. BBC, s.l., out. $2016 b$. Disponível em: <https://goo.gl/bXgSz9>. Acesso em: 1 fev. 2017.

BETTATI, Mario. Droit Humanitaire. Paris: Le Seuil, 2000.

BORGES, Leonardo Estrela. O Direito Internacional Humanitário: a proteção do indivíduo em tempo de guerra. Belo Horizonte: Del Rey, 2006.

BUERGENTHAL, Thomas. International Human Rights in a Nutshell. St. Paul, MN: West Publishing, 1988. 
CANÇADO TRINDADE, Antônio Augusto. Dilemas e Desafios da Proteção Internacional dos Direitos Humanos no Limiar do Século XXI. Revista Brasileira de Política Internacional, Brasília, v. 40, n. 1, 1997.

CANOTILHO, José Joaquim Gomes. Direito Constitucional e Teoria da Constituição. 7. ed. Coimbra: Almedina, 2003.

CARACOL RADIO. La marcha volvió irreversible el proceso de paz: Partido Liberal. Caracol Radio, s.l., 9 abr. 2013. Disponível em: <https://goo.gl/KHvwDi>. Acesso em: 1 fev. 2017.

CENTRO DE NOTICIAS ONU. Colombia: Consejo de Seguridad de la ONU reitera su apoyo al proceso de paz. Centro de Notícias ONU, s.l., 26 ago. 2016. Disponível em: $<$ https://goo.gl/b08aQm>. Acesso em: 1 fev. 2017.

CICCO FILHO, Alceu. Direito Internacional Humanitário e a Atuação da Cruz Vermelha na América Latina. In: Univ. Rel. Int., Brasília, v. 6, n. 1, p. 103-125, jan./jun. 2008.

COLÔMBIA. Acuerdo Final para la Terminación del Conflicto y la Construcción de Una Paz Estable y Duradera. Bogotá, 24 nov. 2016. Disponível em: <https://goo.gl/YbUAIk>. Acesso em: 1 fev. 2017.

COLÔMBIA. "El marco jurídico para la paz implica impunidad”. Colombia, Bogotá, 5 abr. 2013. Disponível em: <https://goo.gl/1sAEgN>. Acesso em: 1 fev. 2017.

COMITÊ INTERNACIONAL DA CRUZ VERMELHA. ¿Qué pasará con el DIH tras la firma de la paz entre el Gobierno de Colombia y las FARC? CICV, Bogotá, 10 ago. 2016d. Disponível em: $<$ https://goo.gl/yS15QV>. Acesso em: 1 fev. 2017.

COMITÊ INTERNACIONAL DA CRUZ VERMELHA. Artigo $3^{\circ}$ comum às quatro Convenções de Genebra. Comitê Internacional da Cruz Vermelha (CICV), Genebra, s.d.a. Disponível em: <https://goo.gl/Ic3WGM>. Acesso em: 1 fev. 2017.

COMITÊ INTERNACIONAL DA CRUZ VERMELHA. Colômbia: acordo de cessar-fogo é um grande avanço para a paz. Comitê Internacional da Cruz Vermelha (CICV), Genebra, 23 jun. 2016a. Disponível em: <https://goo.gl/WNnxd9>. Acesso em: 1 fev. 2017.

COMITÊ INTERNACIONAL DA CRUZ VERMELHA. Colômbia: dez perguntas sobre acordos de paz, acordos especiais e DIH. Comitê Internacional da Cruz Vermelha (CICV), s.l., 27 jun. $2016 \mathrm{~b}$. Disponível em: <https://goo.gl/yO7M3s>. Acesso em: 1 fev. 2017.

COMITÊ INTERNACIONAL DA CRUZ VERMELHA. Colômbia: os desafios humanitários de 2016. CICV, Genebra, s.d.b. Disponível em: <https://goo.gl/AQPHA1>. Acesso em: 1 fev. 2017.

COMITÊ INTERNACIONAL DA CRUZ VERMELHA. Como o Direito Internacional Humanitário define “conflitos armados”? Comitê Internacional da Cruz Vermelha (CICV), Genebra, artigo de opinião, mar. 2008. Disponível em: <https://goo.gl/bq0I78>. Acesso em: 1 fev. 2017. 
COMITÊ INTERNACIONAL DA CRUZ VERMELHA. Editorial: Colômbia, para além da paz. Comitê Internacional da Cruz Vermelha (CICV), s.l., 12 mar. 2015. Disponível em: <https://goo.gl/VQkgnB>. Acesso em: 1 fev. 2017.

COMITÊ INTERNACIONAL DA CRUZ VERMELHA. O acordo final entre o governo e as FarcEP marca um novo rumo para a Colômbia. Comitê Internacional da Cruz Vermelha (CICV), s.l., 25 ago. 2016c. Disponível em: <https://goo.gl/4n9hfg>. Acesso em: 1 fev. 2017.

CONSILIUM. A Proteção da Pessoa Humana no Conflito Armado Colombiano. Consilium. Revista Eletrônica de Direito, Brasília, n. 3, v. 1, jan/abr 2009. Disponível em: <http://www.unieuro.edu.br>. Acesso em: 1 fev. 2017.

CÔRTES, Gustavo. Colômbia: acordo é ponto de partida, ressalvam especialistas. Comunicar, Rio de Janeiro, 16 dez. 2016. Disponível em: <https://goo.gl/sFz0xl>. Acesso em: 1 fev. 2017.

COSOY, Natalio. ¿Por qué empezó y qué pasó en la guerra de más de 50 años que desangró a Colombia? BBC Mundo, Bogotá, 24 ago. 2016. Disponível em: <https://goo.gl/3MIfdV>. Acesso em: 1 fev. 2017.

CROCE ROSSA ITALIANA. Informazioni generali. Roma, 2008. Disponível em: $<$ http://www.cri.it/informazioni.php>. Acesso em: 1 fev. 2017.

DAVID, Éric. Principes de droit des conflits armés. Bruxelas: ULB, 2002.

ECHANDÍA, Camilo. Expansión Territorial de las Guerrillas Colombianas: Geografía, economía y violencia. En: DEAS, Malcom; LLORENTE, María Victoria. Reconocer la guerra para construir la paz (Comp.). Cerec, ediciones Uniandes, Grupo Editorial Norma, Bogotá, fev. 1999.

EL INFORMADOR. Indígenas Wayúu apoyan proceso de paz. El Informador, La Guajira, 24 set. 2012. Disponível em: <https://goo.gl/n0OMBY>. Acesso em: 1 fev. 2017.

EL PAÍS. Acuerdo general para la terminación del conflicto y la construcción de una paz estable y duradera. El País, s. l., 29 ago. 2012. Disponível em: <https://goo.gl/WskhxI>. Acesso em: 1 fev. 2017.

EL PAÍS. OEA ampliará misión de apoyo al proceso de paz. El País, s. l., 26 set. 2016. Disponível em: <https://goo.gl/KYjOM7>. Acesso em: 1 fev. 2017.

EL TIEMPO. Lo que significa que 47 países se comprometan con la paz de Colombia. El Tiempo, s. l., 30 jan. 2016. Disponível em: <https:/goo.gl/oyQ16k>. Acesso em: 1 fev. 2017.

EL UNIVERSAL. Cronología: el proceso de paz en Colombia. El Universal, Bogotá, 24 ago. 2016. Disponível em: <https://goo.gl/TCo3sG>. Acesso em: 1 fev. 2017.

FERNANDES, Jean Marcel. A promoção da paz pelo Direito Internacional Humanitário. Porto Alegre: Sergio Antonio Fabris, 2006. 
FERRY, Stephen. Violentología: un manual del conflicto colombiano. s.l., abr. 2012. Disponível em: $<$ https://goo.gl/oFQvAw>. Acesso em: 1 fev. 2017.

GASSER, Hans Peter. International Humanitarian Law: An Introduction. In: HAUG, H. (Ed.) Humanity for All: The International Red Cross and Red Crescent Movement. Berna: Paul Haupt Publishers, 1993.

GRAJALES, César. El dolor oculto de la infancia. UNICEF-Colombia, Santa Fé de Bogotá, 1999. Disponível em: <https://goo.gl/fljHIW>. Acesso em: 1 fev. 2017.

GUERRA, Sidney. As três grandes vertentes da proteção internacional da pessoa humana: Direito Internacional Humanitário, Direito Internacional dos Direitos Humanos e Direito dos Refugiados: uma introdução. IN: GUERRA, Sidney; PRONER, Carol. Direito Internacional Humanitário e a Proteção Internacional do Indivíduo. Porto Alegre: Sergio Antonio Fabris Editor, 2008.

GUEVARA, Kalki Zumbo Coronel. As Forças Armadas Revolucionárias da Colômbia (FARC) e Sua Atuação no Cenário Internacional. CEDIN: Revista Eletrônica de Direito Internacional, vol. 6, 2010.

INSIGHT CRIME. AUC. InSight Crime: Investigation and Analysis of Organized Crime. Washington, D.C., 17 nov. 2015. Disponível em: <http://www.insightcrime.org>. Acesso em: 1 fev. 2017.

INTERNATIONAL CRISIS GROUP. Los Nuevos Grupos Armados en Colombia. Informe sobre América Latina, n. 20, 10 maio 2007.

LAFER, Celso. Prefácio. In: LINDGREN ALVES, José Augusto. Os direitos humanos como tema global. 2. ed. São Paulo: Perspectiva, 2003.

LAFUENTE, Javier. Após o “não” aos acordos, líderes políticos tentam salvar processo de paz na Colômbia. El País, Bogotá, 3 out. 2016a. Disponível em: <https://goo.gl/HCOzha>. Acesso em: 1 fev. 2017.

LAFUENTE, Javier. Colômbia diz "não" ao acordo de paz com as FARC. El País, Bogotá, 3 out. 2016b. Disponível em: <https://goo.gl/8H4WUe>. Acesso em: 1 fev. 2017.

LAFUENTE, Javier. Govemo e FARC chegam a acordo sobre busca de desaparecidos. El País, Bogotá, 18 out. 2015. Disponível em: <http://brasil.elpais.com/> . Acesso em: 1 fev. 2017.

LAWAND, Kathleen. O que é um conflito armado internacional? Entrevista. 2012. Disponível em: <https://goo.gl/NJLKCV>. Acesso em: 1 fev. 2017.

MARCOS, Ana. ELN e o Governo da Colômbia começarão a negociar em 27 de outubro em Quito. El País, Bogotá, 11 out. 2016a. Disponível em: <https://goo.gl/G0afJn>. Acesso em: 1 fev. 2017.

MARCOS, Ana. FARC fecham acordo e dizem que vão depor armas após 50 anos de guerra na Colômbia. El País, Bogotá, 22 jun. 2016b. Disponível em: <https://goo.gl/4a6DDA>. Acesso em: 1 fev. 2017. 
MARTON, Fábio. FARC na Colômbia: 200 anos de violência. Revista Aventura na História, s.l., 24 nov. 2016. Disponível em: <https://goo.gl/7f266U>. Acesso em: 1 fev. 2017.

NOGUERA, Martha Bottía. La Presencia y Expansión Municipal de las FARC: es avaricia y contagio, mas que ausencia estatal. Documento CEDE: Revista da Universidad de Los Andes, Bogotá, fev. 2003. Disponível em: <https://economia.uniandes.edu.co/> . Acesso em: 1 fev. 2017.

PEJIC, Jelena. The protection scope of Common Article 3: more than meets the eye. International Review of the Red Cross, Volume 93, n. 881, mar. 2011.

PIOVESAN, Flávia. Direitos Humanos e Justiça Internacional. 6. ed. São Paulo: Saraiva, 2015a.

PIOVESAN, Flávia. Direitos Humanos e o Direito Constitucional Internacional. 15. ed. São Paulo: Saraiva, 2015b.

PORTAL DO PLANALTO. Entenda o Acordo de Paz entre o governo colombiano e as Farc. Portal Brasil, Brasília, set. 2016. Disponível em: <https://goo.gl/rz4KP5>. Acesso em: 1 fev. 2017.

POSADA, Jorge Iván. Los empresarios, dispuestos a financiar la paz. El Colombiano, 27 out. 2012. Disponível em: <https://goo.gl/wC2r4V>. Acesso em: 1 fev. 2017.

POSSO, Camilo González. Alternatives to war: Colombia's peace processes. Conciliation Ressources, London, 2004. Disponível em: <https://goo.gl/e9jiMj>. Acesso em: 1 fev. 2017.

RAICH, Jordi. A Colômbia que foi e a que será. Comitê Internacional da Cruz Vermelha, Bogotá, 11 mar. 2014. Disponível em: <https://goo.gl/uHTv0e>. Acesso em: 1 fev. 2017.

RAMOS, André de Carvalho. Processo Internacional de Direitos Humanos. Rio de Janeiro: Renovar, 2002.

RML/EPD [tam]. Colômbia: cronologia do conflito armado. Deustsche Welle, Berlin, ago. 2016. Disponível em: <http://dw.com/p/1IpPc>. Acesso em: 1 fev. 2017.

SÁNCHEZ, Nélson Camilo. Paz na Colômbia. Conectas Direitos Humanos, São Paulo, 7 set. 2016. Disponível em: <https://goo.gl/7O4Bjr>. Acesso em: 1 fev. 2017.

SEGURA, Hugo Garcia. Procuraduría conceptúa que Marco Legal para la Paz es inconstitucional. Bogotá: El Espectador, abr. 2013.

SWINARSKI, Christophe. Direito Internacional Humanitário: como sistema de proteção internacional da pessoa humana: principais noções e institutos. São Paulo: Editora Revista dos Tribunais, 1990.

SWINARSKI, Christophe. Introdução ao Direito Internacional Humanitário. Brasília: Comitê Internacional da Cruz Vermelha/Instituto Interamericano de Direitos Humanos, 1996.

UNIVERSITAT DE BARCELONA. Documentos Colômbia: proceso de paz. Barcelona, s.d. Disponível em: <https://goo.gl/aHhxi4>. Acesso em: 1 fev. 2017. 
VALLADARES, Gabriel Pablo. A contribuição do Comitê Internacional da Cruz Vermelha (CICV) aos últimos avanços convencionais do Direito Internacional Humanitário. IN: GUERRA, Sidney; PRONER, Carol. Direito Internacional Humanitário e a Proteção Internacional do Indivíduo. Porto Alegre: Sergio Antonio Fabris Editor, 2008.

VANGUARDIA. 'Nosotros no elegimos a Santos para que consintiera a las Farc'. Vanguardia, Colômbia, 5 mai. 2013. Disponível em: <https://goo.gl/8aEcs3>. Acesso em: 1 fev. 2017.

VERMELHO. Com a palavra, as vítimas do conflito armado colombiano. Portal Vermelho, São Paulo, 5 jun. 2014. Disponível em: <https://goo.gl/sPJRQi>. Acesso em: 1 fev. 2017.

VIANA, Manuela Trindade; VILLA, Rafael Duarte. Internacionalização pelo envolvimento de atores externos no conflito colombiano: atuação da OEA na desmobilização de grupos paramilitares na Colômbia. DADOS - Revista de Ciências Sociais, Rio de Janeiro, v. 55, n. 2, 2012, p. 403-445.

VITÉ, Sylvain. Typology of armed conflicts in international humanitarian law: legal concepts and actual situations. International Review of the Red Cross, Volume 91, Number 873, mar. 2009.

VIVANCO, José Miguel. A Promessa do Acordo de Paz na Colômbia - e suas falhas. Human Rights Watch, s.l, 27 set. 2016. Disponível em: <https://goo.gl/tqPpRC>. Acesso em: fev. 2016.

\section{JURISPRUDÊNCIA}

CORTE INTERAMERICANA DE DIREITOS HUMANOS. Caso 19 Comerciantes vs. Colômbia. Mérito, Reparações e Custas. Sentença de 5 de julho de 2004. Série C, nº 109.

CORTE INTERAMERICANA DE DIREITOS HUMANOS. Caso das Comunidades afrodescendentes deslocadas da Bacia do Rio Cacarica (Operação Gênesis) vs. Colômbia. Excepciones Preliminares, Mérito, Reparações e Custas. Sentença de 20 de novembro de 2013. Série C No. 270.

CORTE INTERAMERICANA DE DIREITOS HUMANOS. Caso do Massacre de Mapiripán vs. Colômbia. Mérito. Sentença de 15 de setembro de 2005. Série C, $n^{\circ} 134$.

CORTE INTERAMERICANA DE DIREITOS HUMANOS. Caso Las Palmeras vs. Colômbia. Exceções Preliminares. Sentença de 4 de fevereiro de 2000. Série C, ${ }^{\circ} 64$.

CORTE INTERAMERICANA DE DIREITOS HUMANOS. Caso Las Palmeras vs. Colômbia. Mérito. Sentença de 6 de dezembro de 2001. Série C, nº 90.

CORTE INTERAMERICANA DE DIREITOS HUMANOS. Caso do Massacre de Pueblo Bello vs. Colômbia. Sentença de 31 de janeiro de 2006. Série C, nº 140.

CORTE INTERAMERICANA DE DIREITOS HUMANOS. Caso Massacre de Santo Domingo vs. Colômbia. Exceções preliminares, Mérito, Reparações e Custas. Sentença de 30 de novembro de 2012. Série C, $n^{\circ} 259$. 
TRIBUNAL PENAL INTERNACIONAL. The Prosecutor vs. Dusko Tadic. Decisão sobre a Moção de Defesa ao Recurso Interlocutório sobre Jurisdição, IT-94-1-A, 2 de outubro de 1995.

TRIBUNAL PENAL INTERNACIONAL. The Prosecutor vs. Fatmir Limaj, Sentença, IT-03-66T, 30 de novembro de 2005.

Ana Carolina Ribas

Graduanda em Direito pela Universidade Federal do Paraná - UFPR. E-mail: ana.ribas@live.com

Ana Paula Luciani de Carvalho

Graduanda em Direito pela Universidade Federal do Paraná - UFPR. E-mail: ana.luciani@gmail.com

Larissa Ramina

Doutora em Direito internacional pela USP, Professora de Direito internacional da UFPR e Professora do Programa de Mestrado em Direitos Fundamentais e Democracia da UniBrasil. E-mail: raminalarissa@gmail.com 